\title{
MENTAL TRAINING AND INFLUENCE OF TEMPERAMENTAL DIMENSIONS IN PREPARATION OF THE CZECH REPUBLIC WEIGHTLIFTING REPRESENTATIVE IN JUNIOR CATEGORY UNDER 23 YEARS: CASE STUDY
}

\author{
Petr Krol, Dana Štěrbová
}

\begin{abstract}
Background. According to the coaches, the weightlifters of the national team show deficiencies in mental skills, which leads to unbalanced performance at top competitions. Based on the knowledge of the efficacy of mental training (MT) from other sports, it is possible to conclude the potential of the MT in top weightlifting.

Objective. The main aim of the authors was to create and verify a program based on mental training techniques implemented in sports training of weightlifter of the junior category of the Czech Republic, and also to reflect the influence of the competitor's temperamental dimensions on the implementation of the MT program in her sports training.

Methods. Semi-structured interviews with the athlete and the coach before and after the implementation of the mental training program were conducted. A psychodiagnostic tests Test of attention $\mathrm{d} 2$ and TEZADO measuring attention resp. temperamental dimensions were used in addition to subjective statements. Self-assessing scales were also used to obtain more quantitative data.

Results. Results showed that some of the mental training techniques had a positive effect on deficient mental skills. These mental skills are crucial in the preparation of the weightlifting representative and can have a significant influence on a sports athlete's performance. The most significant difference was achieved in the skill of refocusing and the smallest difference in imagination. According to the subject, the influence of the temperamental dimensions on the mental training program had a significant impact in connection with the refocusing and anger coping.

Conclusion. Mental training techniques can help top weightlifters to overcome the mental skills deficiencies used in their sports training, which may have a positive influence on performance in both training and competitions. Self-knowledge of the temperamental dimensions is significant to the success of the program.
\end{abstract}

Keywords: weightlifting, qualitative evaluation, mental skills, temperament, sport psychology

Received: 26. 1. 2020

Approved: 16. 11. 2020

Published online: 29. 12. 2020 


\section{Introduction}

Mental training (MT) is included more and more often in sports preparation. The current research strategy focuses on finding out the effectiveness of mental training (Tod, Hardy, \& Oliver, 2011). Authors report a positive effect of using a systematic training of mental skills on performance (Behncke, 2004; Holliday, Burton, \& Sun, 2008; Horn, 2008; Judge, 2011; Makaruk, Porter, \& Makaruk, 2013; Orlick, 2008; Pelka et al., 2016). The Polish study results showed that the concentration training using the neurofeedback method supports the accuracy of tennis players, ie fewer unforced errors, outs, and more serves to lines (Gracz, Walczak, \& Wilińska, 2007). According to Fournier, Calmels, Durand-Bush, and Salmela (2005) the mental skills training appear to be most effective, if it includes imagination, relaxation, activation, focusing, and refocusing. They found out that gymnast achieves a five percent performance increase compared to the control group that did not complete the mental skills training.

Makaruk et al. (2013) examined the influence of mental training - specifically attention focusing - in the shot put - sport close to weightlifting. Research participants achieved better performance - longer shot puts in the external focus of attention than in the internal focus of attention.

The training of the top weightlifters is strongly oriented to the increase of performance through the increase of strength. Ranganathan, Siemionow, Liu, Sahgal, and Yue (2004) concluded that the "mental training group" improved the cortical output signal. That leads muscles to a higher activation level and increases the abduction strength of the little finger and flexion elbow joint.

Sherouse (2016) outlines the ethnological description of the preparation of the Georgian weightlifting representation. According to him, lifting maximum weights requires intensive usage of physical and mental forces. He described various aspects of sports training as psychological dimensions of performance, motivation, group dynamics, and health.

Many studies explore personality aspects or temperament in context with the sport. For example, Tohanean and Chicomban (2010) find out that the profile of choleric-sanguine temperament is characteristic for the practitioners of individual sports. Further, the pattern of temperament and personality in athletes along with its potential influence on athletic performance was studied (Bauger, Eisemann, \& Vangberg, 2014; Bukowska \& Zgadzaj, 2007; Han et al., 2006; Siwek et al., 2015).

According to Leźnicka et al. (2017), athletes practicing martial arts differed significantly with regard to the intensity of three temperamental dimensions - Preservation, Sensory sensitivity, and Emotional reactivity in comparison to non-athletes. Temperamental characteristics may also indicate higher resilience of the nervous system in martial arts in comparison to non-athletes.

Blecharz and Siekańska (2012) state that athletes who achieve top performance are characterized by a similar level of skills, however, not always by the same individual characteristics such as temperamental dimensions. Mental training of the professional athlete should be individualized, and dimensions of temperament should always be taken into consideration also.

Based on the above information, ie the statements of representative coaches, description of the application of MT elements in a representative team of Georgia, the efficiency of using MT in strength sports, and importance of personality aspects our research was supposed to come 
close to possibilities of using MT in sports preparation of weightlifters and clarify the role of temperamental dimensions in it.

Several authors are engaged in research and publication in the field of sport psychology, ie psychological training in sport in the Czech Republic. The main literature is Sport psychology of Slepička, Hošek and Hátlová (Slepička et al., 2011) and Selected Chapters from Sport Psychology of Blahutková and Sližik (Blahutková \& Sližik, 2014). Kavková resp. Vičar and Hřebíčková, for example, deal with individual topics of psychological preparation and diagnostics - How does imagery help in sport? (Kavková et al., 2013), Mental skills among Czech athletes: Validation of the Czech version of OMSAT-3* questionnaire (Vičar \& Hřebíčková, 2017).

\section{Objective}

The main aim of the authors was to create and verify a program based on mental training techniques implemented in sports training of weightlifter of the junior category of the Czech Republic, and also to reflect the influence of the competitor's temperamental dimensions on the implementation of the MT program in her sports training.

Sub-objectives of the research:

1. Identify the key mental skills of a junior weightlifter in relation to training and competitions.

2. Design the program of mental training in connection with the identification of key mental skills of the weightlifter.

3. Assess the effectiveness of the mental training program in terms of increasing the level of mental skills needed in weightlifting.

4. To find out how the temperamental dimensions of the weightlifter affected the implementation of the MT program in her sports training.

Research questions

1. Which mental skills of a junior weightlifter are underdeveloped in context to training and competitions?

2. What changes in the level of mental skills occur when the program is included in the sports training of a junior weightlifter?

3. What increase in the level of sports performance occurs by including the program in sports training?

4. How did the temperamental dimensions of the junior weightlifter affect the implementation of the MT program in her sports training?

\section{Methods}

\section{Characteristics of the participant}

We used an intentional selection of the participant. The criterion was the membership in the weightlifting, as well as the achieved performance resp. membership in the Czech youth national team for up to 23 years. These representatives regularly compete in the Czech National 
League and the Czech Republic Championship, as well as international tournaments, the European Championship and the World Championship. Another criterion of the selection was a significant motivation to include new procedures in the sports training and above all a good overview of the level of the mental skills. The research participant in this case study was a woman -22 years old.

\section{Procedures and techniques}

The core of our research was an analysis of the psychological training program and the influence of the temperamental dimensions on it. One case meets the requirements of the qualitative research, but we also used psychodiagnostic tests, so overall it is mixed research. Attention Test d2 (Brickenkamp \& Zillmer, 2000), Questionnaire TEZADO (Smékal, 2003), and simple self-assessment scales were used to produce quantitative data. These data were processed in a case report. The overlap of potential gaps due to the subjective response of the examined person is the reason for this quantitative addition. Such a study of top-level taekwondo mental training was conducted by Lim and Sullivan (2016).

The first step was the administration of the TEZADO temperamental dimensions questionnaire to the weightlifter. We preserved received test data, scoring, and interpretation that were conducted after the MT program completion. This procedure was chosen because of minimizing the influence of known with data on the MT program. Then we carry out semistructured interviews with the weightlifter and the trainer to map the level of mental skills that can be included in the training of young weightlifters under 23 years of age. The list of partial techniques of the MT program was compiled based on the obtained information and theory. MT program was focused primarily on increasing the level of cognitive skills. The selection was made from Lesyk's list of mental skills (1998). These skills are basic - self-confidence, goal setting, commitment, psychosomatic skills - stress response, fear coping, relaxation, activation, and cognitive skills - focusing attention, re-focusing, imagination.

Our MT program consisted of three important phases: educational, training, and practical. In the educational phase, athletes are educated about the importance of improving mental skills and relationship with performance. An important step is to explain to participants how they can learn mental skills, similar to physical skills. The educational phase lasted two hours. The training phase focuses on specific strategies and techniques. Training of mental skills was connected with the training of physical skills. The practical phase had three primary objectives: (a) automation of the mental skills, (b) teaching the athlete to systematically integrate psychological skills into competition situations, and (c) simulating the skills that athletes will use in competition situations (Hřebíčková, 2013).

Techniques chosen for our MT program were focusing, refocusing, and anger coping. Researchers claim that the ability to focus intensively on tasks and resist environmental stimuli is an important component of an athlete's performance (Johnson, Hrycaiko, Johnson, \& Halas, 2004; Nideffer, 1976; Orlick, 2012; Orlick \& Partington, 1988). The focusing then defines several characteristics:

1. focus width (narrow $\mathrm{x}$ wide)

2. focus direction (internal $x$ external)

3. focus shift (switching the focus of the focus in performance situations)

4. awareness of attention focus (intentional $\mathrm{x}$ unintentional) 
Anger coping is a complex skill. Components were psychosomatic skill - relaxation and cognitive skill - cognitive restructuring (Cognitive behavioral therapy based). Cognitive restructuring intervention used e. g. Didymus \& Fletcher (2017).

The psychodiagnostic test was chosen to test relevant skills. The inclusion of the partial techniques of the MT in a program of psychological preparation was the next step. Then a timetable for an entire preparatory period was drawn up. Continuous data were collected during the program concerning the evaluation of its phases - education, training, and practice in training or competition. The researcher was not present in all (physical) training units during the implementation of the MT program so another source of research data is a mental skills training diary. It provides greater insight into the practical phase of the MT program. The training diary is semi-structured, and it is also a tool of the weightlifter during the MT program and a final evaluation. The selected psychodiagnostic test was administered again after that. The results of both tests were case-processed. Then the weightlifter competes in a peak event of the season - the European Championship under 23 years. In the end, the final evaluation of the whole program and the influence of the temperamental dimensions on the program took place. Both the competitor and the trainer made the evaluation, which was carried out through semi structured interviews.

We selected the TEZADO questionnaire because it is a relatively economical tool in terms of administration time and simplicity of evaluation. This tool contains 90 items, ie. 10 for each of the nine dimensions of the questionnaire. Test Scales (dimensions) are Emotivity, Echoing, Activity, Width of the consciousness field, Polarity, Avidity, Sensory Focus, Sensitivity, and Rational focus. In our research, we worked only with focusing, refocusing, and anger coping. Attention can be measured by the $\mathrm{d} 2$ test, which is also intended for the field of sport psychology. Anger coping was measured by a simple scale. Ottawa Mental Skills Assessment Tool (OMSAT-3) focuses on twelve mental skills (Vičar \& Hřebíčková, 2017) and it was too extensive for our purpose.

\section{Methods of data processing and analysis}

We record data as audio on a digital recorder. The transcriptions of interviews were done by the researcher, the text material was further analyzed in the ATLAS.ti computer program.

The first part of the data analysis was done to assess the MT program. The data coding procedure was used for data analysis (Corbin \& Strauss, 2015). The codes from the units were merged by the cluster analysis method. The triangulation technique was used to check the validity of data collection. Specifically, data triangulation has been performed using various data (Corbin \& Strauss, 2015). The first source was the evaluation of the MT program by the athlete, then the trainer and the last source was the psychodiagnostic test with the rating scale. The crucial source was the response of the athlete. The coach can only describe observable behavior and the test methods do not offer a detailed analysis of changes in the level of mental skills or their causes. Another reason is the limited number of standardized tests on the Czech population. Therefore we could not test all mental skills.

The second part of the data analysis was done to assess the influence of an athlete's temperamental dimensions on the MT program in terms of process. The data coding procedure and the cluster analysis method was used. Sources were the evaluation of the athlete, the trainer, and also the result of the temperamental dimensions questionnaire TEZADO. The crucial 
source was the response of the athlete because of the precondition of self-knowledge and because of questionnaire limits.

\section{Ethical aspects of research}

Ethical rules protecting research participants were followed, the informed consent of the participants was obtained, and the research was approved by the Ethics Committee of Faculty of Physical Culture Palacký University Olomouc. The objectives, circumstances, and the potential benefits, as well as the potential limits of the research, were explained to the research participants in detail. Emphasis was placed on the emotional safety of the participants and reciprocity. The research did not endanger the physical or mental health of the subjects.

\section{Results}

The research outputs are divided into four semantic units - A. statement of the competitor before the implementation of the MT program, B. statement of the competitor after the ending of the MT program using the mental skills training diary, C. analysis of psychodiagnostic methods and scales. D. statements of the coach.

A. The competitor had a basic theoretical knowledge about MT. However, she did not systematically practice MT. She mentioned factors that negatively affect her performance in training and competition. Lack of concentration was the main deficiency in the competition. It led to the failure in achieving the expected performance, as well as frustration and anger directed to her team, especially to the coach.

She said she was explosive and choleraic sometimes. She is unable to correct it and regrets her actions with hindsight if there is an explosion of rage. She believes that this is a significant factor in her failure. Situations occur is at a lower frequency in training than in competitions. The selection of MT techniques, which are used to effective coping with anger and aggression followed this phenomenon. Weightlifter described her "fluctuating attention" also. "I cannot concentrate myself one hundred percent on a race. Failure and its consequences are running through my head." A similar situation is during training, but she has more time to concentrate. The techniques of focusing and refocusing were also included in the MT program based on this statement of the competitor, Subject was satisfied with other mental skills and was not interested in extending the program with other techniques. The researcher's additional questions did not mention another area in which the competitor would see dissatisfaction. According to the competitor, the expected outcome at the end of the MT program was the stabilization of mood and attention.

B. The competitor first mentioned active cooperation with the trainer in the training of the mental skills in the final evaluation, which was going on after the European Championship. But the most important thing for her was persistence. The exercise and the practical part of the MT program failed for a long time. At first, she did significant progress in focusing. She rates it as "the easiest task of the entire program". But she failed to keep this attention concentrated when distraction occurred, and it was difficult to refocus on. She experienced frustration with failure often when she was practicing this skill. She was upset about herself and her inner speech had a negative connotation. 
She said it was difficult and exhausting for her. But she was aware that the change might not come immediately, and she was ready to persevere. The athlete also practiced progressive muscle relaxation in circumstances with anger coping skills. The process was similar to refocusing - it took a longer time to succeed. "I felt too excited to relax. I am not used to doing it and I often tend to be hyperactive. At first, the relaxation seemed endless." However, she also reflected minor improvements with the help of her mental diary It gave her confidence and a desire for further improvement. According to her an important aspect of change is selfreflection because through her diary she began to perceive her thoughts, feelings, and body response. All of it led to a calming down in training and racing situations. The competitor describes that she did not perceive practically any change in improving the refocusing and progressive muscle relaxation from the beginning to the competitions of the National League and the Czech Championship. However, she started to feel the greatest progress before the European Championship when she was able to repeat the training performance. Improved mental skills helped her whit it. "The performance was quite successful, although two attempts were not valid. I was satisfied with myself ". Based on this experience, the weightlifter decided that she had managed the MT techniques that were part of the program. But at the top competition - European Championship under 23, she found deficiencies in other mental skills which she did not use during training and which has a negative effect on performance. This finding opens up another space for research or deeper cooperation with a sports psychologist. The findings also indicate that the results of the study conducted during one competition season are limited they do not have the value of longitudinal research.

The competitor was asked about the influence of her temperamental dimensions on the MT program. She responds that the influence of the temperamental dimensions was great. "I have generally a choleric temperament and my personality actually projects into training, races, and sports in general. During the program, I realized that it was in me and that I should think about myself. But I started to think about it more at the end of the program, just before my anger coping changed fundamentally." The competitor further states that she realized that she couldn't change her personality in terms of temperament. But if she says it out loud, it might be beneficial to her. "I am just upset because of the trifle. What should I do now to refocus on training, competition? Overall according to the subject the influence of the temperamental dimensions on the MT program was significant in connection with the refocusing and anger coping.

C. The Attention Test d2 (Brickenkamp \& Zillmer, 2000) has been administered as an attention diagnosis. The following attention variables can be compared from the test results: Total count, Total performance, Omission error, Replacement error, Concentration performance (VS), and Percentage of errors. For our research was crucial VS. It is an indicator of the concentration of attention. Other variables are not so significant in the context of the study also because the weightlifter has a time limit of one minute according to the rules and concentrates for a shorter time than completing the test. The subject achieved 96 points in primary testing after conversion to a standard score. An average value is 100 points on a scale from 70 to 130. The result of the competitor was 107 points in final testing after the completion of the MT program. In the individual comparison, the value increased by 11 points. Based on this comparison, we can conclude that the competitor has increased the level of her attention concentration, which could have affected her sports performance. Other quantitative outcomes were obtained from simple self-assessment scales. Scales are delimited by points 1 and 10, 1 meaning "I can focus very little on training" and 10 "I can focus on the training and racing at 
the highest possible level". The competitor's self-assessment was compared in a total of five main scales. All scales are associated with training or racing situations. Focusing - before 7, after 8 , difference 1 . Refocusing - before 2, after 7, difference 5 . Anger coping - before 2, after 7, difference 5 . Relaxation - before 3 , after 7 , difference 4 . In all scales there was a positive shift - the smallest difference was 1 point, and the highest difference was 5 points. These differences fully correspond to the final evaluation of the competitor.

TEZADO results of a subject in most scores were average. Emotivity (E) and Primarity (P) vs. Secondary (S) scores were significantly increased. Score E reached 17. Score P 15 and S 1. Emotivity is a sensitivity and susceptibility of the psychic apparatus to stimuli that activate the organism and psyche, ie, the tendency to excitement even in stimuli that leave others calm, as well as the easiness of mobilizing energy potential. Great emotivity means a tendency to fall into chaos in stressful situations. Primarity is the disposition of the psychic apparatus to keep the psychic contents shorter time. Primary people live for a moment, they are mobile, impulsive, quickly changing their sympathy, looking for new stimuli, expecting immediate results, so their reactions are accelerated, spontaneous, impulsive.

D. The semi structured interview conducted with the coach was moderated from the general principles of weightlifting preparation to the details of the competitor's mental skills. According to the trainer, the main problems of weightlifting representation are: "performance instability, which means that weightlifters work hard and prepare for a long time and give it everything. Then take place European and World Championship and dumbbell falls, invalid attempts accumulate..." The coach could not comment in detail this phenomenon in a connection with the subject, because her representation career is not so long. However, he is convinced that this phenomenon is also related to her. The coach also said that "this competitor is gaining experience" and he is trying to help her. Her frequent outbursts of rage directed at him trainer evaluate as a barrier: "If I could choose what the MT program would contain, it would be positively a calming exercise or something that would help resolve competitor's explosiveness. Otherwise, I am quite satisfied, and I cannot think of anything else to improve in psychological preparation. Except for concentration. "He also added he had a positive experience with a competitor who had to cooperate with sports psychologist externally.

He considered changes in the preparation of the competitor as: "Well the shift after that time is great. In the beginning, no big changes. She became still angry easily, and sometimes it was perhaps even worse. But then, after about two months, it suddenly changed, and her workouts were more stable and the anger was decreasing." The coach admitted that he was trying to react differently than before the program started and he was trying to provide constructive criticism to the competitor. He also stated that he observed greater deliberation and concentration at the end of the preparation. He agreed with the competitor that he did not see the change at the national level at the beginning of the preparation. Overall, he evaluates positively the MT program.

The coach also described the influence of the temperamental dimensions on the MT program. "I would say the competitor is fiery. I try to perceive the personality of all weightlifters, but I would say that both calm and unstable weightlifter can be successful. It probably depends on how they approach it. "He cannot imagine that temperament is directly modified, but that it is a part of psychological preparation. Overall, the coach evaluates the competitor is more stable and coping her rage, which affects the balance of performance. Vice 
versa according to him, the MT program affects the temperamental dimensions respectively its demonstration.

\section{Discussion}

The overall rating of the weightlifting MT program is positive. The competitor answered that she has learned some of the techniques and used their effects in training and competition. Some studies report the positive effect of using systematic training of mental skills (Behncke, 2004; Holliday et al., 2008; Judge, 2011; Tod et al., 2011).

The competitor considered refocusing as the most effective of the MT techniques. The subject in a training often failed to shift her attention to desirable impulses and remained unconcentrated before the implementation of the MT techniques into her sports training. The quality of the training and the sports performance has improved by mastering the refocusing. The competitor used mainly self-instructional internal speech to refocus her attention. Internal speech efficiency is confirmed by research from the football environment of Johnson, Hrycaiko, Johnson, \& Halas (2004).

The competitor did not perceive a fundamental difference before and after the implementation of the MT program in the focusing. She explained it by a higher level of this skill at the beginning of the research. If we looked at the result of the Attention Test $\mathrm{d} 2$ after primary testing statistically, we would find that the competitor's result was average.

The subject used relaxation techniques primarily in the context of anger coping. The competitor took a longer time to be able to use this skill effectively as with refocusing. Pineschi and Di Pietro (2013) reported a positive effect of using relaxation techniques on reducing prematch anxiety or arousal regulation.

An important change for the weightlifter was an increased level of anger coping. Techniques of relaxation and refocusing through internal speech helped her to achieve it. An important role played the trainer who was not only an unknown observer but a participant in the research, who did not limit his competitor.

The difference between the results of the Attention Test $\mathrm{d} 2$ before and after the implementation of the MT program is positive. Also in all self-assessment scales, there was a minimum improvement of at least one point. The coach observes changes in the concentration of the competitor's attention and in minimizing the occurrence of behavior that disturbs this concentration. Personal weightlifting records increased. It could be considered as an objective fact. Additional space to increase the level of mental skills may be uncovered during research. This fact suggests the potential of long-term cooperation of a competitor with a sports psychologist who can respond appropriately to these findings in terms of creating and implementing other, previously unused, MT techniques.

The aim of such a program is a self-functioning where the competitor's innovations can be beneficial. Long-term application of the MT techniques seems necessary (Hřebíčková, 2013) because of the diversity of competition situations and the psychological development of an athlete. In this context, the causes of potential performance changes seem difficult to understand due to the number of variables that occur in the preparation process. However, the reflection of the competitor, the sports psychologist, and their mutual interaction can help. Statement based on the imminent subjective experience of the weightlifter with the MT program could not be 
replaced by the results of the attention test, which is directly related to one of the improved mental skills. The psychodiagnostics of the temperamental dimensions have proved to be successful in this case, as the results correlated with the behavior of the athlete in sports training both before and during the MT program. However, this consensus cannot be generalized. Competitor benefit from evaluating the program itself and from an acquaintance with the results of the test methods. She thinks deeper about the MT techniques and learns what has she done successfully and what gap for improvement it has. She also better understands why she improves some mental skills more slowly than others. Further valuable findings could be brought by a comprehensive multi-case study of MT in young weightlifters using multiple test methods to maximize the objectivization of the results, which is limited by a low number of cases.

\section{Conclusion}

Continuous data collection - before, during, and after the implementation of the MT program brings valuable knowledge. This could be used to implement and improve the process of the MT program for weightlifting trainers, athletes, and sports psychologists, but also for the wider public of Czech weightlifting. An important benefit for the competitor is the acquisition of procedures that helped her to regulate mental phenomena during the training and competition process. The competitor requires a long-term, systematic, and periodic training of the MT techniques. In retrospect, she underlines the crucial role of self-knowledge at the beginning of the process, which deepens self-reflection, gives context to situations of a sport failure. Furthermore, it reduces the pressure for change at all costs by reception unchanging aspects of personality - temperament. The essence of the effectiveness of such a program is to take into account the needs of the competitor and knowing her personality at least basically. This leads to identification with the program, increased motivation, and understanding of its potential benefits and potential limits, cases.

\section{References}

Bauger, L., Eisemann, M., \& Vangberg, H. C. (2013). Personality traits among junior elite athletes in Norway, and a comparison with their non-athletic counterparts. Athletic Insight, $5(2), 145-162$.

Behncke, L. (2004). Mental skills training for sports: A brief review. Athletic Insight, 6(1), 119.

Blahutková, M., \& Sližik, M. (2014). Vybrané kapitoly z psychologie sportu. Masarykova univerzita.

Blecharz, J., \& Siekańska, M. (2012). Wykorzystanie diagnozy temperamentu w opracowaniu indywidualnego treningu mentalnego na przykładzie zawodników klasy światowej. Rozprawy Naukowe, 37, 110-118.

Brickenkamp, R., \& Zillmer, E. (2000). Test pozornosti d2. Testcentrum.

Bukowska, K., \& Zgadzaj, R. (2007). Comparative analysis of the temperament of chess and football players against a background of the general population. Human Movement, 8(2), 89-97.

Corbin, J., \& Strauss, A. L. (2015). Basics of qualitative research: Techniques and procedures for developing grounded theory (4th. ed.). SAGE. 
Didymus, F. F., \& Fletcher, D. (2017). Effects of a cognitive-behavioral intervention on field hockey players' appraisals of organizational stressors. Psychology of Sport and Exercise, 30, 173-185. https://doi.org/10.1016/j.psychsport.2017.03.005

Fournier, J. F., Calmels, C., Durand-Bush, N., \& Salmela, J. H. (2005). Effects of a seasonlong PST program on gymnastic performance and on psychological skill development. International Journal of Sport and Exercise Psychology, 3(1), 59-77. https://doi.org/10.1080/1612197X.2005.9671758

Gracz, J., Walczak, M., \& Wilińska, K. (2007). Seeking new methods of mental training in sport. Studies in Physical Culture \& Tourism, 14(1), 97-102.

Han, D. H., Kim, J. H., Lee, Y. S., Soo, J. B., Soo, J. B., Kim, H. J., Sim, M. Y., Sung, Y. H., In, K. L. (2006). Influence of temperament and anxiety on athletic performance. Journal of Sports Science and Medicine, 5(3), 381-389.

Holliday, B., Burton, D., \& Sun, G. (2008). Building the better mental training mousetrap: Is periodization a more systematic approach to promoting performance excellence? Journal of Applied Sport Psychology, 20, 199-219. https://doi.org/10.1080/10413200701813889

Horn, T. S. (Ed.). (2008). Advances in sport psychology (3rd. ed.). Human Kinetics.

Hřebičcková, H. (2013). Mentální trénink v př́pravě alpských lyžařu juniorů [Doctoral dissertation]. Fakulta tělesné kultury, Univerzita Palackého v Olomouci.

Johnson, J. J. M., Hrycaiko, D. W., Johnson, G. W., \& Halas, J. M. (2004). Self-talk and female youth soccer performance. The Sport Psychologist, 18(1), 44-59. https://doi.org/10.1123/tsp.18.1.44

Judge, L. W. (2010). Developing a mental game plan: mental periodization for achieving a "flow" state for the track and field throws athlete. The Sport Journal, 13(4), 1-35.

Kavková, V., Malůš, M., Taušová, J., \& Válková, H. (2013). How does imagery help in sport? Studia Sportiva, 7(2), 123-127. https://doi.org/10.5817/StS2013-2-15

Krol, P., \& Štěrbová, D. (2019). Mentální trénink v přípravě reprezentantky České republiky ve vzpírání v juniorské kategorii do 23 let: př́ípadová studie. Tělesná kultura, 42(1), 1-8. https://doi.org/10.5507/tk.2018.005

Lesyk, J. J. (1998). The nine mental skills of successful athletes. In Annual Conference of the Association for the Advancement of Applied Sport Psychology. Hyannis.

Leźnicka, K., Starkowska, A., Tomczak, M., Cięszczyk, P., Białecka, M., Ligocka, M., Żmijewski, P., Pawlak, M. (2017). Temperament as a modulating factor of pain sensitivity in combat sport athletes. Physiology \& Behavior, 180, 131-136. https://doi.org/10.1016/j.physbeh.2017.08.018

Lim, T., \& O'Sullivan, D. M. (2016). Case study of mental skills training for a taekwondo olympian. Journal of Human Kinetics, 50, 235-245. https://doi.org/10.1515/hukin-20150161

Makaruk, H., Porter, J. M., \& Makaruk, B. (2013). Acute effects of attentional focus on shot put performance in elite athletes. Kinesiology, 45(1), 55-62.

Nideffer, R. M. (1976). Test of attentional and interpersonal style. Journal of Personality and Social Psychology, 34(3), 394-404. https://doi.org/10.1037/0022-3514.34.3.394

Orlick, T. (2008). In pursuit of excellence (4th. ed.). Human Kinetics.

Orlick, T., \& Partington, J. (1988). Mental Links to Excellence. The Sport Psychologist, 2, 105-130.

Pelka, M., Heidari, J., Ferrauti, A., Meyer, T., Pfeiffer, M., \& Kellmann, M. (2016). Relaxation techniques in sports: A systematic review on acute effects on performance. Performance Enhancement \& Health, 5(2), 47-59. https://doi.org/10.1016/j.peh.2016.05.003 
Pineschi, G., \& Di Pietro, A. (2013). Anxiety management through psychophysiological techniques: Relaxation and psyching-up in sport. Journal of Sport Psychology in Action, 4(3), 181-190. https://doi.org/10.1080/21520704.2013.820247

Ranganathan, V. K., Siemionow, V., Liu, J. Z., Sahgal, V., \& Yue, G. H. (2004). From mental power to muscle power - gaining strength by using the mind. Neuropsychologia, 42(7), 944-956. https://doi.org/10.1016/j.neuropsychologia.2003.11.018

Sherouse, P. (2016). Skill and masculinity in Olympic weightlifting: Training cues and cultivated craziness in Georgia. American Ethnologist: Journal of the American Ethnological Society, 43(1), 103-115. https://doi.org/10.1111/amet.12266

Siwek, M., Dudek, D., Drozdowicz, K., Jaeschke, R., Styczen, K., Arciszewska, A., Akiskal, K. K., Akiskal H. S., Rybakowski, J. K. (2015). Temperamental dimensions of the TEMPS-A in male and female subjects engaging in extreme or/and high risk sports. Journal of Affective Disorders, 170(1), 66-70. https://doi.org/10.1016/j.jad.2014.08.036

Slepička, P., Hošek, V., \& Hátlová, B. (2011). Psychologie sportu. Karolinum.

Smékal, V. (2003). Temperamentově - zaměřenostní dotazník TE-ZA-DO konstrukce, standardizace, interpretace, vyhodnocení. In Temperament, jeho struktura, funkce a diagnostika. FF UJEP. https://is.muni.cz/el/1423/jaro2005/psy140/um/TE-ZADO_vytah.pdf

Tod, D., Hardy, J., \& Oliver, E. (2011). Effects of self-talk: A systematic review. Journal of Sport \& Exercise Psychology, 33(5), 666-687. https://doi.org/10.1123/jsep.33.5.666

Tohanean, I. D., \& Chicomban, M. (2010). Personality and performance sport. Science, Movement and Health, 10(2), 609-613.

Vičar, M., \& Hřebíčková, H. (2017). Mental skills among Czech athletes: Validation of the Czech version of OMSAT-3* questionnaire. Studia Sportiva, 11(1), 165-181.

\begin{abstract}
About the authors
Mgr. Petr Krol currently works as a sports psychologist for the Czech Weightlifting Association and a school psychologist at a primary school. He also studies Ph.D. program in Kinanthropology, specializing in Psychological Kinanthropology at the Faculty of Physical Culture of Palacký University in Olomouc. He specializes in counseling, coaching, psychotherapy, mental training, and research.
\end{abstract}

Contact details:

Address: Antošovická 254/170, 71100 Ostrava

E-mail: petr.krol01@upol.cz

Doc. PhDr. Dana Štěrbová, Ph.D. is a university teacher in the field of kinanthropology at the Faculty of Physical Culture of Palacký University in Olomouc and clinical psychologist. Her interesting topics are families and children, couple dyads, people with disabilities, sexuality, and relationships, sport psychology, supervision, research.

\title{
Contact details:
}

Address: Faculty of Physical Culture, Palacký University, tř. Míru 117, 77900 Olomouc

E-mail: dana.sterbova@upol.cz

Krol, P., Štěrbová, D. (2020). Mental training and influence of temperamental dimensions in preparation of the Czech Republic weightlifting representative in junior category under 23 years: case study. E-psychologie, 14(4), 31-42. https://doi.org/10.29364/epsy.383 